\title{
Systematic Instruction and Job Coaching Strategies
}

\author{
Anthony Shay* \\ University of Wisconsin-Stout Vocational Rehabilitation Institute, USA
}

Submission: July 12, 2017; Published: July 27, 2017

*Corresponding author: Anthony Shay, University of Wisconsin-Stout Vocational Rehabilitation Institute, USA; Tel: 608-606-2459; Email: tafts4268@gmail.com

\begin{abstract}
Job coaching in the vocational rehabilitation professions is an important service provided to individuals with disabilities in employment. The instruction is not simply a structured approach but is designed to address specific consumer needs. Utilization of a variety of different coaching strategies maximizes job coaching and learner efforts. The very nature of job coaching is consumer skill building leading to vocational growth Effective job coaching leads to consumer job satisfaction, development of greater meaning regarding work tasks, increased program effectiveness, and meaningful programmatic outcomes.
\end{abstract}

Keywords: Vocational Development; Systematic Instruction; Job Coaching; Vocational Rehabilitation; Learning

\section{Introduction}

Systematic Instruction (SI) is ubiquitous in vocational rehabilitation service provision when it comes to job coaching. Task analysis is a process through which the elements that comprise a work task become explicit, including relationships, roles, and contexts [1]. Breaking tasks down makes teaching and learning them easier. It places each task element in sequential order so consumers can more readily see how each piece fits with others in the work flow. It also facilitates a better understanding of the expectations of coworkers who may perform tasks before and after a consumer's task. Coaches can facilitate meaning-making with consumers regarding the impacts on task engagement they have on the processes coworkers involved in the processes within which their work is situated.

\section{Discussion}

Systematic instruction is a method of describing a process through which information is presented to a consumer by a job coach. Coaches must believe a person has the capacity to develop beyond their current developmental level. This is a process of intentionality, focused on the development of deeper meaning, and transcending the initial task toward generalizing this meaning to other tasks [2].The instruction is individualized and structured around specific consumer needs. Job coaching should never reflect a cookiecutter approach to task teaching. Without consumer-centered coaching services, job coaching programs sacrifice consumer job satisfaction,job meaning, and program effectiveness and meaningful programmatic outcomes. SI builds on task acquisition to include reinforcement of effective work behavior toward greater vocational competence and self-efficacy.

As tasks are learned the job coach fades to allow as much consumer independence as possible. Whenever implementing a coaching strategies, it is important to establish a baseline from which to measure progress. Coaching efforts (for each work task) are provided based on needs through monitoring progress. As reported by the U. S. Department of Education in the Final Report of the National Mathematics Advisory Panel [3]. Recommendations for student systematic instruction includes:

a) Instructor explanation and demonstration toward student verbal problem solving.

b) Deliberate ordering of task elements to identify key components of the activity.

c) Regular student contact and explicit feedback regarding effective task completion.

There is no one-size-fits-all approach to working with consumers in vocational rehabilitation. The strategies for the implementation of these recommendations may come in a variety of forms. 
Job coaches use a variety of coaching strategies to engage consumers within work tasks. Strategies employed are designed to provide consumers with feedback toward effective skill development. Consumers have unique needs given their functional limitations and therefore require varying levels of assistance with task acquisition and reinforcement of appropriate task engagement activity [4]. The provision of some level of assistance toward task acquisition is based on a prompting level or hierarchy $[5,6,7]$ the hierarchies can be ascending or descending in terms of the intensity of the assistance-from less-to-more or from more-to-less, respectively. A more-to-less hierarchical approach reflects the initial task acquisition process-the learning side of the zone of proximal development. A less-to more approach is reflective of building task skills over time and increasing independence within task engagement-crossing over to the development side of the zone of proximal development [8].

Prompt fading, as opposed to fading the job coaching entirely, typically involves providing these strategies and reducing the level of assistance as the consumer becomes more independent. Prompt fading refers to the task acquisition process. Job coach fading may need to consider task engagement activity other than those directly related to learning a particular task or task element (i.e. hard skills versus soft skills). MacDuff, Krantz, and McClannahan state that fading must be done prudently since fading instructional strategies ineffectively can have deleterious consequences for the consumer which include "prompt dependence, passivity, and the development of error patterns that can be difficult to correct" [9]. Hebb described a stimulusresponse condition he defined as motivational drift [10] akin to a condition Csikszentmihalyi referred to as psychic entropy [11].

Dependence, passivity, errors, and waning motivation all reflect task disengagement. Likewise, levels of very high stimulation or very low stimulation may also precipitate task disengagement [12]. These typically occur when there is an ineffective balance between vocational challenges and vocational competence: anxiety is too high or low, challenges are too high or low and the consumer may be receiving too much or too little stimulation. Systematic and planful fading can avert negative effects that jeopardize job stabilization. Job coaching strategies may include (list is not exhaustive):

a) Assistive Technology: Using AAC devices, computer technology (e.g. alarms, modified clock faces, iPad, word completion or prediction, word processing software), checklists, picture boards, etc. may facilitate task engagement activity.

b) Delayed Prompting: Allowing for a time lag before providing a prompt. Delayed prompting is used with repetition and verbal cueing with the length of the lag time between the task engagement verbal cue incrementally increasing until maximal duration is achieved or no further prompting is necessary for task engagement to occur. Pre-established lag times may also be determined as a constant delayed prompt (e.g. always wait 5 seconds). [13].

c) Direct Verbal Prompting/Direct Auditory Cueing: Directly engaging the consumer verbally with task instructions.

d) Foreshadowing: Providing task anticipatory guidance in advance of later task elements or tasks. This differs from prompting or cueing in that foreshadowing occurs relatively early in the task acquisition process as a means to reinforce task anticipation and planning.

e) Full Physical Assistance: This typically refers to high levels of cuing and generally involves a handover- hand type of instruction.

f) Gestures: Task engagement activity is directed and encouraged by the job coach through the use of gestures and nonverbal expression.

g) Incremental Prompting/Graduated Guidance: Focused on a stepwise task acquisition process whereby a consumer and job coach work together learning task elements until the entire task is learned.

h) Ignoring: Not providing a response to behavior or verbalizations as a means to avoid reinforcing Undesirable behavior or verbalizations.

i) Indirect Verbal Prompting/ Indirect Auditory Cueing: Indirectly verbal engagement with the Consumer using leading statements intended to prompt effective self-direction.

j) Instruction: Written or verbal directions provided at the outset of a task are typically not considered prompting or cueing but are a typical method of providing task information from which subsequent prompts and cues may be necessary for task maintenance.

k) Modeling/Demonstration: Role modeling or demonstrating the expected task engagement activity or task elements can facilitate vicarious learning by the consumer. [14]

1) Role Playing/Simulation: This is a variation of the role modeling/demonstration but specifically targets performing less concrete or tangible tasks. The focus here is on the transmission of more tacit than explicit knowledge.

m) Monitoring: Can be done overt or covertly to gauge independence and level of assistance required.

n) Natural Cueing: A naturally occurring task engagement condition which indicates the need for the elements of a task to be completed. There is no active prompt fading since this is a naturally Occurring cue.

o) Partial Physical Assistance/Physical Priming: This involves less than full or intermittent physical cuing and may be graduated as required by the consumer up to full cuing. 
p) Positional Prompting: Positioning expected task engagement behavioral indicators in such a manner as to indicate a correct course of action.

q) Positive Reinforcement: providing affirmations to a consumer reinforcing the expected or desired behavior when it occurs toward maintaining and building task engagement behavior.

r) Repetition: Allowing a consumer to perform a task or task element on their own over multiple trials can facilitate or cement learning. Role modeling through successive trials can be instrumental in task acquisition as well.

s) Silence: Silence can be used strategically to encourage a consumer to think through task steps or to encourage consumer self-directed activity.

t) Visual Prompts: Refer to the use of pictures, icons, and items as a means to elicit responses from consumers.

\section{Conclusion}

It is important to maintain flexibility in job coaching strategy selection based on the needs of the consumer. Building rapport is also important when engaging consumers. Intentionality, nonverbal syncing behavior, eye contact, proximity to the consumer, informed choice, and empathy can facilitate rapport building. Disruptions in the psychological/behavioral flow of a consumer need mediation and resolution toward job maintenance $[15,16,17]$.

Furthermore, Bruner references the "Zeigarnik Effect" which also informs consumer task engagement for a job coach. According to Bruner "to achieve a sense of accomplishment requires a task that has a beginning and some terminus" [18] the effect, in brief, relates to the influence of interruptions within the temporal sequence of a task as having a greater impact on task completion and recall than a sequence without an interruption. By their nature coaching strategies tend to build into a task acquisition process structured interruptions. Job coaching by its very nature is a defining factor in the facilitation of, and enhancement in, the development of consumer vocational competence, task meaning, and job satisfaction [19].

\section{References}

1. Watson DE, Llorens L A (1997) Task analysis: An occupational performance approach. American Occupational Therapy Association, Bethesda, Maryland, USA.

2. Feuerstein R, Falik LH, Feuerstein RS (2015) Changing Minds \& Brains:
The Legacy of Reuven Feuerstein. Teacher's College Press, New York, USA.

3. Greeno JG, Collins A (2008) Commentary on the final report of the national mathematics advisory panel. Educational researcher 37(9): 618-623.

4. Fadely DC (1987) Job Coaching in Supported Work Programs. Stout Vocational Rehabilitation Institute, University of Wisconsin-Stout, Washington, USA.

5. MacDuff GS, Krantz PJ, Mc Clannahan LE (2001) Prompts and prompt-fading strategies for people with autism. Making a difference: Behavioral intervention for autism 37-50.

6. Wehman P, Inge KJ, Revell WG, Brooke VA (2007) Real work for real pay: Inclusive employment for people with disabilities. MD: Paul H. Brookes Publishing Co.

7. National Professional Development Center on Autism Spectrum Disorders. (2017). Steps for Implementation: Least-to-Most Prompts.

8. Vygotsky LS (1978) Interaction between learning and development In M. Cole, V. John-Steiner, S. Scribner, \& E. Souberman (Eds.), Mind in Society: The Development of Higher Psychological Processes. (79-91). Cambridge, MA: Harvard University Press.

9. MacDuff GS, Krantz PJ and McClannahan LE (2001). Prompts and prompt-fading strategies for people with autism. Making a difference: Behavioral intervention for autism 37-50.

10. Hebb DO (1949) Organization of behavior: A neuropsychological theory. John Wiley \& Sons, New York, USA.

11. Csikszentmihalyi M (1990) Flow: The psychology of optimal experience. Harper Perennial, New York, USA.

12. Liem AD, Lau S, Nie Y (2008) The role of self-efficacy, task value, and achievement goals in predicting learning strategies, task disengagement, peer relationship, and achievement outcome. Contemporary Educational Psychology 33(4): 486-512.

13. Wehman P, Inge KJ, Revell WG, Brooke VA (2007) Real work for real pay: Inclusive employment for people with disabilities. Brookes Publishing Co, Baltimore, Maryland, USA.

14. Bandura A (1997) Self-efficacy: The exercise of control. WH Freeman and Company, New York, USA

15. MacDuff GS, Krantz PJ, McClannahan LE (2001) Prompts and promptfading strategies for people with autism. Making a difference: Behavioral intervention

16. Wehman P, Inge KJ, Revell WG, Brooke VA (2007) Real work for real pay: Inclusive employment for people with disabilities, Brookes Publishing Co, Baltimore, Maryland, USA.

17. National Professional Development Center on Autism Spectrum Disorders. (2017) Steps for Implementation: Least-to-Most Prompts.

18. Bruner JS (1996) The culture of education. Harvard University Press, Cambridge, Maryland, USA.

19. Shay AF (2017) Entwistle's epistemology: Job coaching for meaning. Global Journal of Addiction \& Rehabilitation Medicine 1(2): 1-3. 
This work is licensed under Creative Commons Attribution 4.0 License DOI:_10.19080/PBSIJ.2017.5.555659

\section{Your next submission with JuniperPublishers} will reach you the below assets

- Quality Editorial service

- Swift Peer Review

- Reprints availability

- E-prints Service

- Manuscript Podcast for convenient understanding

- Global attainment for your research

- Manuscript accessibility in different formats

( Pdf, E-pub, Full Text, Audio)

- Unceasing customer service

Track the below URL for one-step submission https://juniperpublishers.com/online-submission.php 